\title{
The potential of cooperative networks to leverage tourism in rural regions
}

\author{
Vítor José Domingues Mendonça \\ Polytechnic Institute of Bragança \\ Mirandela, Portugal \\ mendonca@ipb.pt
}

\author{
Carlos R. Cunha \\ Applied Management Research Unit (UNIAG) \\ Polytechnic Institute of Bragança \\ Mirandela, Portugal \\ crc@ipb.pt
}

\author{
Elisabete Paulo Morais \\ Applied Management Research Unit (UNIAG) \\ Polytechnic Institute of Bragança \\ Mirandela, Portugal \\ beta@ipb.pt
}

\begin{abstract}
Rural tourism can be an opportunity to perform the development of the most disadvantaged rural areas. In this pursuit, there are many challenges to face for make this sector competitive and economically viable. This paper focuses on develop a better understanding of rural tourism and the need for cooperative paradigms that can leverage its competitiveness. In this context, a conceptual model and a technology-based system is presented to bridge the gap between heritage resources and business opportunities to enable regional development.
\end{abstract}

Keywords - rural tourism; cooperation; model; business opportunities; information system.

\section{INTRODUCTION}

The desertification and recession in rural areas is a global phenomenon, which has worsened over the last few years. However, today, rural areas have more functions than just agricultural production. They are places of recreation, tourism, leisure, ancestral food production, consumption and ecommerce [1]. This evolution made rural areas increasingly taking advantage from tourism and invested in their cultural and natural heritage to align with the growing demand for rural and natural tourism [2], [3]. This new reality showed that rural areas have increasingly benefitted from tourism and start to invest in their cultural and natural heritage to meet the growing demand for rural [2], [4]. In this context, it can be said that there is an enormous potential that can be economically feasible.

In recent years we have been assisting in Portugal the formulation and systematic implementation of national and local policies for rural development that favor the tourism sector. These policies aim to induce the sustainable development of rural areas and stimulate the diversification of the economic activities of those who live in such areas by harnessing their endogenous resources [5].
However, there are several factors that determine success as well as the development of rural tourism. In this context we can highlight as conditioning factors: a complete tourism package, good community leadership, support and participation of local government, sufficient funds for tourism development, strategic planning, coordination and cooperation between business people and local leadership, coordination and cooperation between rural tourism entrepreneurs, information and technical assistance for tourism development and promotion, good convention and visitor bureaus and widespread community support for tourism [6], [7]. We also emphasize the interrelation between these factors and which affect the sector's competitiveness.

Whereas the concept of competitiveness expresses the capacity of firms, economies or regions to remain in the competition taking place internally and internationally and to gain certain economic advantages from it, competitiveness representing the driving force at the basis of efficiency and economic progress [8]. The competitiveness in the tourism sector is related to the ability to increase tourism expenditure, to increasingly attract visitors while providing them with satisfying, memorable experiences, and to do so in a profitable way, while enhancing the well-being of destination residents and preserving the natural capital of the destination for future generations [9].

The problem is that the rural tourism industry is characterized by small firms where a lack of trust and cooperation predominates [10]. These constraints have created problems in the rural tourism sector, reflecting the need for technical assistance to destinations and rural organizations to develop management strategies. Also, the shift from a basic rural economy to a new economic specialization involves experimentation, learning processes, new capabilities, new policies, adjustment and reconfigurations [11].

In the context of rural tourism is essential to create cooperation networks that favoring competitiveness and the 
complementarity of companies [12], allowing economic agents offer a wider range of products and services to its customers [13].

The Information and Communication Technologies (ICT) assume a role that facilitates the constitution of cooperation networks, making easier the development of alliances, allowing to create of virtual organizations with other business partners and to develop interorganizational information systems that support strategic business relationships, with clients, suppliers, subcontractors and others [13], [14].

This paper represents an ongoing effort to combine ICT and cooperation mechanisms between the main economic operators in rural tourism sector as an appropriate strategy to promote rural regions as well as their economic activity.

\section{TOURISM AND RURALITY}

Rural tourism experience, understood as a global experience of the destination, experienced by visitors from rural areas, involves a great amount and variety of resources, attractions, services, people and environments, not all designed specifically for tourist use, but which condition the experience, and are the target of tourist demand. Thus, the potential of tourism experience in these rural destinations is very dependent on the resources and heritage (both material and immaterial) in the villages and surrounding territory [15].

Therefore, rural tourism is a sector of tourism industry targeted at using natural, cultural-historical and other resources for tourist products development. This field characterized by small tourism business is oriented towards tourists' active rest and recreation in villages [16]. However, the tourism industry, especially rural tourism, is largely dominated by small and medium sized enterprises (SMEs) and is often considered less innovative than other industries [17].

According to Komppula, a significant number of studies shows how the small tourism firms and entrepreneurs can make a crucial impact on the development and operation of a destination [7]. Rural tourism has thus become a new, relevant factor in rural development, drawing tourist flows into rural areas and contributing to a better spatial and temporal distribution of these flows [18]. For this drawing, one key issue is the identification of destination stakeholders, because they provide funding, tourism superstructure, product and support programmes that influence governance [19].

In order to support stakeholders' expectations, the existent rural services providers must be able to transform their genuine resources and skills in solid tourism offer. However, player present several debilities in their offer, emerging the need of establish cooperation mechanisms among players.

Only trough cooperation, often referred to as synergies, we can assure that several complementary activities are enforced, benefiting all these activities and at the same time contribute to a common objective [20].

Understanding the role of cooperation, and how to operationalize it, is essential to designing new business and technology models to drive to more competitiveness and richness in rural regions.

\section{THE ROLE OF COOPERATION}

The structuring of the business system, and the development profile of what is commonly referred to as business, has changed drastically over the last few decades. From a clearly verticalized structuring, we moved to a model clearly transverse. This new form of structuring, to a certain extent, reflects a growing need for interoperability between organizations whose long-term business perspective has long since ceased to be isolated. We operate more and more in a globalized world where organizations need to work in groups to survive.

Manuel Castells notes that the traditional models that persist in many organizations do not fit the characteristics of the current market. He goes even further, stating that the traditional model of organization, based on vertical integration and functional management hierarchy, is in crisis. On the one hand, large companies are not versatile to the point of responding in a timely manner, on the other hand, small companies do not reach the scale necessary to be innovative and truly competitive [21].

The concept of interorganizational cooperation emerges as such.

Ultimately, the current organizations demand an enormous capacity to have flexible structures and the ability to develop and to dissolve partnerships between organizations, is, per se, a critical success factor. The concept of organizational cooperation, however, is not a recent innovation, since it is described in organizational theory in the 1980s and 1990s, according to the organizational network perspective [22].

More recently a breakdown / decomposition of the concept of cooperation, which was perhaps initially too far-fetched, has been manifested in multiple ways of structuring the broad concept of cooperation. According to some authors we can classify the different forms of cooperation by analyze and distinguish aspects such as: objectives [23], temporal persistence [24] or degree of interconnection [25].

It is relevant to refer to the multidisciplinarity associated with the concept of organizational cooperation. The act of cooperating requires the fulfilment of multiple requisites necessary for its operationalization: from the necessary relationship of trust among cooperators, to the technological support capacity, to an adequate homogeneity in the own state of organizational maturity of each cooperator (e.g. capacity of response to the inputs of the partners, guarantees of fulfillment of their role in a competitive way), financial capacity to invest, or even the capacity to evolve and mature over time the own topology and degree of cooperation.

As such, these dimensions range from social to technological, to economic, to the existence of common values and to a close alignment with the strategic concept of evolution and approach to the market. Irrespective of the focus of study of the phenomena of cooperation, of the nomenclatures with 
which the various researchers classify it, there is a broad consensus in the fact that organizational cooperation contributes to an improvement in the efficiency of organizations and the existence of competitive gains in many aspects such as: increasing market power [26], cost reduction and capacity for innovation [27]

The cooperation should be considered as strategic because it enables cooperating organizations to develop joint strategies and, consequently, to obtain and maintain competitive advantages.

The purpose of cooperation is to obtain synergy effect, on the outcome that the relationship represents more than the sum of its parts.

\section{ROLE OF ICT IN TOURISM COOPERATION}

The tourism sector incorporates a high diversity level of activities, organizations and partnerships, being one appropriated environment for the establishment of interorganizational networks. [28], [29]. The tourism sector is most suitable to the study of networks because he presents two important factors - fragmentation and geographical spread. The cooperation between tourism operators, as well as between tourism operators and local leadership have been identified as success factors in rural tourism development [30].

The concept of cooperation is based on the premise that the best results are achieved when the elements of a group proceed in accordance with the individual and group interests. This view is underpinned by the gains that can come from interconnecting different data, sources of information, resources, skills and knowledge. In a heterogeneous group we can try to reduce individual weaknesses through the complementarity of each element.

Organizations are looking for new business models that can evolution of its business activity and its external environment. The concept relationship has become crucial to the success of organizations. Organizations are much more interconnected, and it is interconnection translates and materializes the concept of cooperation network, which can be defined as the ability of organizations to establish cooperation between them, through an efficient interconnection of their business supported by ICT.

Information technology systems are central to these networks as they act as integrators and facilitators by representing, reproducing, and enabling the particular resource and activity constellations [20].

Several authors agree that technology and information systems facilitate the relationship between tourist organizations and the customer, and also contributes to the promotion and specialization of tourism products. This can be advantageous if these technologies respond to the needs felt by the users delineated with the objectives of the tourism companies, enabling a relationship that responds satisfactorily to the client and also identify problems in the organization products or in the organization itself [31].

ICT have the opportunity to present solutions of added value to traders who operate with rural tourism. The ability, particularly in rural tourism, to take advantage of information technologies can be a key factor in increasing competitive capacity and success [32].

Among other factors, ICT systems can improve interactions in cross-functional as well as geographically dispersed teams and can also improve operational capabilities of knowledge workers in complex process settings, and usually several different ICT systems and application software are used in parallel, often during a limited time frame, to support specific tasks or phases [20].

Thus, we must consider that, currently ICT plays a preponderant role to structure and streamline cooperative relationships.

\section{How to Make LeVerage of Rural Tourism: CONCEPTUAL MODEL}

Considering the context of tourism in rural regions, and especially in disadvantaged regions, where small economic operators are dominant, it is essential to create conditions and promote ways to increase their competitiveness. As such, the model that will be presented below intends to create synergies between the small agents and to promote cooperative arrangements, and consequently, increasing the capacity of installed response.

In this section, a conceptual model is presented that allows the development of a computer system in which several economic agents share information to enable and facilitate a tourism operator to create tourist packages.

The model assumes that in the rural world there is a great variety of resources and skills that may be a source of tourist attraction, such as: customs and traditions, festivities, food, natural resources and genuine products.

However, each of these resources and skills, if sold alone, its economic viability is residual.

In this sense, will be possible to create tourism packages based on resources and skills, provided by several small economic agents, with the aim of leveraging their potential.

The precepts underlying the conceptual model are schematized in the following figure (Figure 1).

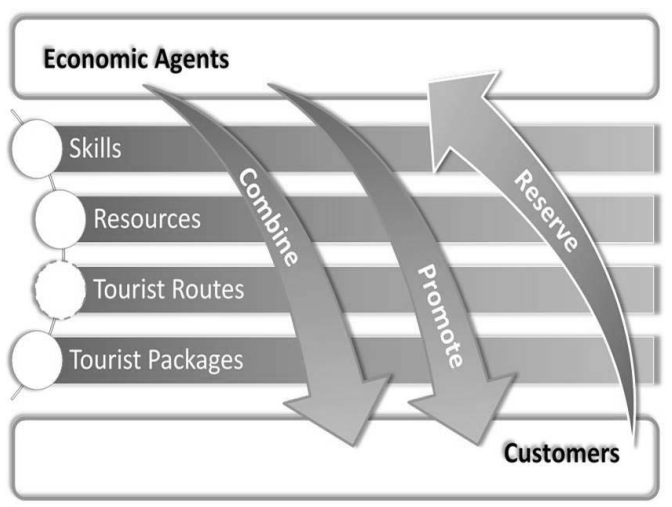

Figure 1. Guidelines of the conceptual model 
As it can be seen in the figure, it is intended that the conceptual model allows that the resources and aptitudes of several economic agents can be combined, around tourist packages and, possibly, around touristic routes.

The system that will support the model should also allow to promote and facilitate the cooperative business.

The model (Figure 2) is based on sharing of information between economic agents, tourism operators and customers, allowing to create comprehensive tourist packages and with complementary skills and resources, to meet all the clients' needs.

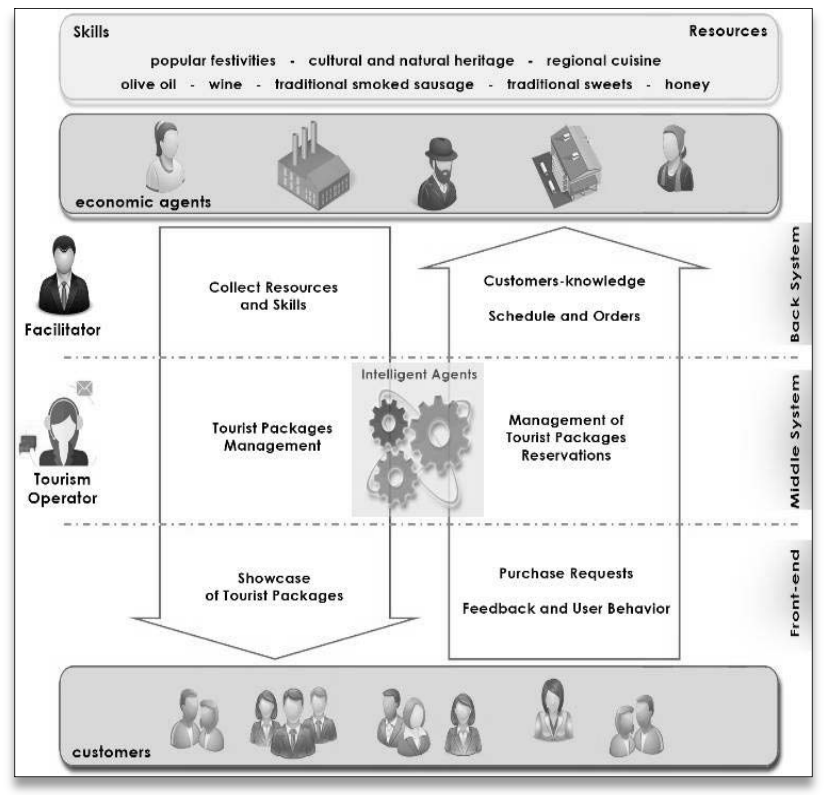

Figure 2. Conceptual model to develop cooperative tourism

The proposed model has four types of actors: economic agents, facilitator, tourism operator and customers.

- Economic agents: are all agents that possess skills and/or resources of potential tourist interest and have economic value in order to be provided in the form of products and services.

These agents may be diverse, such as: the small farmer who can supply genuine products; a local accommodation unit; a craftsman; a regional cuisine; a restaurant; an olive oil factory; a local producer or a smoked sausage factory; a cultural association; a recreational association, a museum; a festivities stewards committee; an event organization enterprise; a local government institution; among others.

- Facilitator: their role is to mediate and facilitate the collection of information about skills, resources and who can provide them. If we consider that economic agents in the rural world may have difficulties with the use of technologies, the facilitators agents allow this barrier may be overcome.
- Tourism operator: are agents that operate in the tourism sector and will be responsible for the organization of tourist packages composed of a wide range of products and services.

- Customers: will be all customers or potential clients with access to technologies with interest in rural tourism and who can consult the offers and make reservations.

The conceptual model establishes a continuous flows of information exchanged between the different actors involved in the cooperative arrangement. These flows of information can be in downstream direction (economic agent, tourism operator and, finally, customers) or in upstream direction (customers, tourism operator and finally, economic agent).

The computational system that supports the model is structured in three layers:

\section{A. Back System}

At this layer, the system provides all the functionalities and interfaces necessary for the interaction of economic agents and facilitators with the system.

As such, initially the system should allow collecting of information on resources, skills and also on the agents that can provide them. On the other hand, the system will allow the scheduling of the supply of products and services to the economic agents or even in an intermediated way by the facilitator.

\section{B. Middle System}

This system layer is oriented to support the functionalities inherent in the management of tourist packages and the management of the reserves, being operationalized by the tourism operator.

The system should also extract knowledge based on the behavior of customers and the experience gained, in the sense of, over time, improving the service provided.

The intelligent agents, identified in the model, intend to automate the analysis of tourist customers' behavior to generate knowledge that will allow economic agents (suppliers) to respond to expectations of their customers. Automated data analysis will also enable tourism operators to do design and organize adequately packages.

\section{Front-end}

The front-end system should be constituted by a diverse set of technologies and interfaces that allow potential customers to be offered the tourist packages, this intends to be a kind of a marketplace of tourist packages, that is to say, a showcase of tourist packages. Consequently, the system should allow customers to place purchase requests.

The system should allow the interaction of customers to collect their feedback, as well as data about their user-behavior, these data will allow to feed the intelligent agents.

From at the model presented previously, it will be possible to derive another model that allows the design and 
management of tourist routes (Figure 3), in which it will be possible to manage routes around the tourist attractions and consonants with the tourist packages.

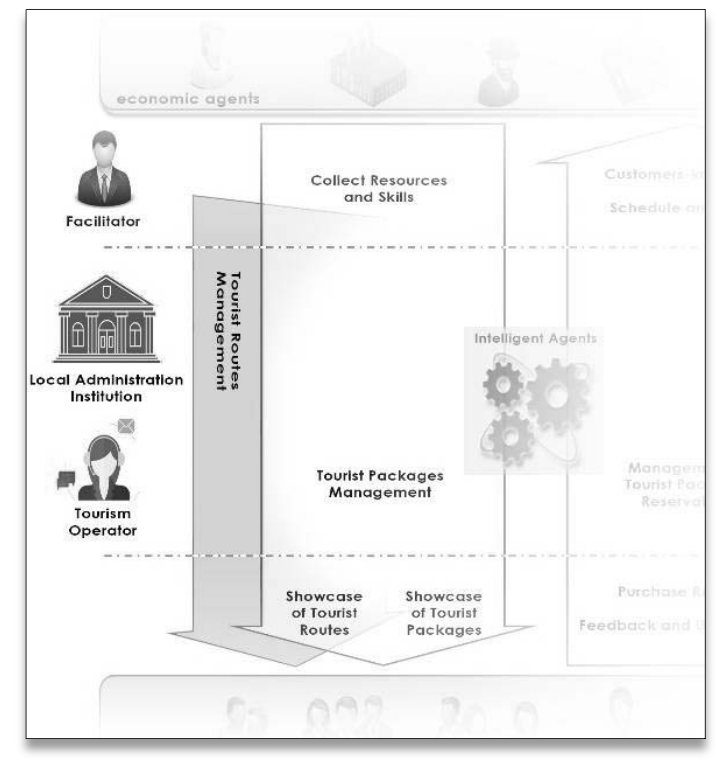

Figure 3. Conceptual model to develop cooperative tourist routes

As can be seen from the figure, this model includes another actor, institution of local administration, responsible for structuring the tourist routes.

In this context, all the resources, skills, economic agents and tourist packages should float around the tourist routes to be created. Therefore, customers will be able to obtain, from the system, more and better information, being able to consult the tourist routes, the offer of touristic packages, as well as the packages associated with the routes.

In this model, the intelligent agents also have an additional role, in the sense of suggesting to the tourism operators, the design of tourist packages for a determined route in which there are gaps in the offer at a given moment, and for which there are available economic agents with compatible skills and/or resources.

As already mentioned, the conceptual model presented will be supported by a technology-based information system (Figure 4). For this, the system is based on a set of ICTs that will make it possible to speed up the permanent communication between the various actors involved in the cooperative arrangement.

As can be seen in the figure, the system is structured in three subsystems (back system, middle system and front-end), each of which is oriented towards different technologies, activities and actors.

The "Back System" can be used by economic agents and facilitators, who can access the system through a responsive web interface. As such, it can be accessed by most ICT equipment.
The "Middle System" is the form of access to the functionalities of the system in which the tourism operators can organize tourist packages, just as the administrative institutions can design tourist routes. Considering the complexity of the functionalities, the interaction interface should be especially oriented for use in computer or technologies with screens of significant size.

The "Front-End" is constituted of web interfaces that allows customers and / or potential customers to consult the tourist offers as well as place orders. Additionally, the system must collect data permanently on the interaction of users in order to feed intelligent agents. The application of trips tourist is intended to be a "companion" application that will assist the tourist, whereas as monitor the behavior of the tourist during the travel experience.

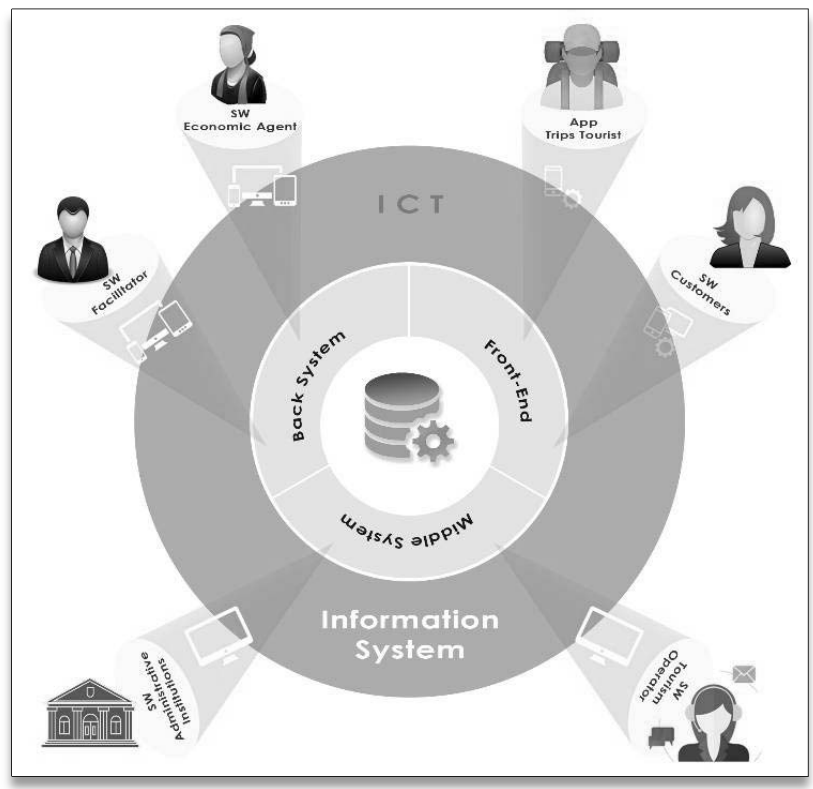

Figure 4. Information system to support the model

In the figure, it can also be verified that the information system is supported by a database and data collecting and analysis agents.

Thus, with the implementation of the system and the model, presented here, we intend:

- promote and facilitate the creation of cooperative networks between various actors operating in the tourism sector, and in particular in rural tourism;

- contribute to a system that allows combine different players, resources and skills to achieve competitive gains;

- increase the responsiveness of rural tourism, as well as make it smarter.

In brief, we can affirm that this conceptual model and the system that supports it are intended to leverage tourism in rural regions. 


\section{CONCLUSIONS}

Rural regions typically have a small, fragile, fragmented economy. This reality presents problems in terms of competitiveness, as well as the robustness of its ability to respond to current market demands.

In this context, the need to establish cooperation networks among different players emerges as indispensable to leverage not only the tourism sector but also a whole regional economy.

It will also be important to create technological cooperative platforms able to support cooperation networks and to identify, leverage and materialize new business offers and to extract knowledge for the continuous improvement of the adequacy between the supply and demand of tourism products and services. A cooperation-based approach will strengthen the tourism sector in rural areas, which at present have a poorly integrated supply and a low response capacity to the increasingly demanding new tourist-profile.

This paper, after frame the concept of the rural tourism and the foundations of cooperation, presented a cooperative business model to leverage rural tourism, allowing resources and skills to be combined around packages and tourist routes. The model is supported by a technology-based system, and promotes that various actors can cooperate in order to create synergies, complementarity and increase their competitiveness.

Finally, some considerations are made about how technologically the proposed business model can be materialized.

\section{ACKNOWLEDGMENT}

UNIAG, R\&D unit funded by the FCT - Portuguese Foundation for the Development of Science and Technology, Ministry of Science, Technology and Higher Education. UID/GES/4752/2016.

\section{REFERENCES}

[1] G. Saxena, G. Clark, T. Oliver, and B. Ilbery, "Conceptualizing integrated rural tourism,” Tour. Geogr., vol. 9, no. 4, pp. 347-370, 2007.

[2] G. Cánoves, L. Herrera, and M. Villarino, "Turismo rural en España: paisajes y usuarios, nuevos usos y nuevas visiones," Cuad. Tur., vol. 15, pp. 63-76, 2005.

[3] J. Gao and B. Wu, "Revitalizing traditional villages through rural tourism: A case study of Yuanjia Village, Shaanxi Province, China," Tour. Manag., vol. 63, pp. 223-233, 2017.

[4] B. Besteiro, "El Turismo Rural En Galicia. Análisis De Su Evolución En La Última Década,” Cuad. Tur., vol. 17, pp. 25-49, 2006.

[5] L. Silva, "Os impactos do turismo em espaço rural," Antropol. Port., vol. 22, no. 23, pp. 295-317, 2006.

[6] S. Wilson, D. R. Fesenmaier, J. Fesenmaier, and J. C. Van Es, "Factors for success in rural tourism development," J. Travel Res., vol. 40, no. 2, pp. 132-138, 2001.

[7] R. Komppula, "The role of individual entrepreneurs in the development of competitiveness for a rural tourism destination - A case study," Tour. Manag., vol. 40, pp. 361-371, 2014.

[8] D. TĂNASE and A. TĂNASE, "The Concept of Competitiveness in the Economic Theory,” Ann. Eftimie Murgu Univ. Resita - Econ. Stud., vol. Fascicle I, 2013.
[9] J. Ritchie and G. Crouch, The competitive destination: a sustainable tourism perspective. CABI Publishing, 2003.

[10] C. Jesus and M. Franco, "Cooperation networks in tourism: A study of hotels and rural tourism establishments in an inland region of Portugal," J. Hosp. Tour. Manag., vol. 29, pp. 165-175, 2016.

[11] F. Randelli, P. Romei, and M. Tortora, "An evolutionary approach to the study of rural tourism: The case of Tuscany," Land use policy, vol. 38, pp. 276-281, 2014.

[12] M. Mariani, R. Baggio, D. Buhalis, and C. Longhi, Tourism Management, Marketing, and Development: The Importance of Networks and ICTs. Palgrave Macmillan, 2014.

[13] V. Mendonça, J. Varajão, and P. Oliveira, "Cooperation Networks in the Tourism Sector: Multiplication of Business Opportunities," Procedia Comput. Sci., vol. 64, pp. 1172-1181, 2015.

[14] J. A. O'Brien and G. Marakas, Management Information Systems. McGraw-Hill/Irwin, 2010.

[15] E. Kastenholz et al., Reinventar o turismo rural em Portugal - cocriação de experiências turísticas sustentáveis. 2014.

[16] O. Paresishvili, L. Kvaratskhelia, and V. Mirzaeva, "Rural tourism as a promising trend of small business in Georgia: Topicality, capabilities, peculiarities," Ann. Agrar. Sci., 2017.

[17] S. Cosma, D. Paun, M. Bota, and C. Fleseriu, "Innovation - A Useful Tool in the Rural Tourism in Romania," Procedia - Soc. Behav. Sci., vol. 148, pp. 507-515, 2014.

[18] A. M. Campón-Cerro, J. M. Hernández-Mogollón, and H. Alves, "Sustainable improvement of competitiveness in rural tourism destinations: The quest for tourist loyalty in Spain," J. Destin. Mark Manag., vol. 6, no. 3, pp. 252-266, 2017.

[19] L. R. Sheehan and J. R. B. Ritchie, "Destination stakeholders: Exploring identity and salience," Ann. Tour. Res., vol. 32, no. 3, pp. 711-734, 2005.

[20] S. V. Rehm and L. Goel, "Using information systems to achieve complementarity in SME innovation networks," Inf. Manag., vol. 54, no. 4, pp. 438-451, 2017.

[21] M. Castells, The Rise of the Network Society: The Information Age Economy, Society, and Culture. Blackwell Publishers Inc, 2010.

[22] J. C. Jarillo, “On strategic networks,” Strateg. Manag. J., vol. 9, no. 1, pp. 31-41, 1988 .

[23] S. a Petersen and M. Gruninger, "An agent-based model to support the formation of virtual enterprises," Int. ICSC Symp. Mob. Agents Multiagents Virtual Organ. E-Commerce, no. January, 2000.

[24] W. Faisst, "Information Technology as an Enabler of Virtual Enterprises: A Life-cycle-oriented Description," Proc. Eur. Conf. Virtual Enterp. Networked Solut., 1997.

[25] A. B. D. S. Júnior, A empresa em rede: desenvolvendo competências organizacionais. Editora Campus, 2007.

[26] P. J. Dimaggio and W. W. Powell, "The Iron Cage Revisited: Institutional Isomorphism and Collective Rationality in Organizational Fields," Am. Sociol. Rev., vol. 48, no. 2, pp. 147-160, 1983.

[27] M. Beeby and C. Booth, "Networks and inter-organizational learning: a critical review," Learn. Organ., vol. 7, no. 2, pp. 75-88, May 2000.

[28] R. Baggio and C. Cooper, "Knowledge Management and Transfer in Tourism: An Italian Case,” Adv. Tour. Res. 2008, no. May, pp. 1-10, 2008.

[29] K. Pavlovich, "The evolution and transformation of a tourism destination network: The Waitomo Caves, New Zealand," Tour. Manag., vol. 24, no. 2, pp. 203-216, 2003.

[30] E. Panyik, C. Costa, and T. Rátz, "Implementing integrated rural tourism: An event-based approach," Tour. Manag., vol. 32, no. 6, pp. 1352-1363, 2011.

[31] B. Aldebert, R. J. Dang, and C. Longhi, "Innovation in the tourism industry: The case of Tourism@," Tour. Manag., vol. 32, no. 5, pp. 1204-1213, 2011.

[32] A. C. H. C. D. Pego, "Sistemas e Tecnologias de Informação no Turismo em Espaço Rural. Estudo da Região Algarve," Universidade Aberta, 2014. 